\title{
The formation mechanism of characteristic region at crack initiation for very-high-cycle fatigue of high-strength steels
}

\author{
Youshi Hong*, Xiaolong Liu, Zhengqiang Lei, Chengqi Sun \\ LNM, Institute of Mechanics, Chinese Academy of Sciences, Beijing 100190, China
}

\section{A R T I C L E I N F O}

\section{Article history:}

Received 10 September 2015

Received in revised form 25 November 2015

Accepted 30 November 2015

Available online 12 December 2015

\section{Keywords:}

Very-high-cycle fatigue

Fatigue crack initiation

Fine-granular-area

Nanograins

High-strength steels

\begin{abstract}
A B S T R A C T
For high-strength steels, the crack initiation of very-high-cycle fatigue (VHCF) is commonly at the interior of material with fish-eye (FiE) morphology containing a fine-granular-area (FGA) surrounding an inclusion as crack origin, and FGA is regarded as the characteristic region of crack initiation. Here, we carefully examined the micro-morphology of FGA and FiE for two high-strength steels. The results revealed that the microscopic nature of FGA is a thin layer of nanograins. Then we proposed the formation mechanism of FGA: Numerous Cyclic Pressing (NCP) between originated crack surfaces, which causes grain refinement at originated crack wake and therefore the formation of FGA. The results of second set experiment showed that the cases with negative stress ratios exhibit the prevalence of nanograin layer in FGA region and the nanograin layer vanishes for the cases with positive stress ratios, which is a verification of the proposed NCP model.
\end{abstract}

(c) 2015 Elsevier Ltd. All rights reserved.

\section{Introduction}

Fatigue failures of metallic materials may happen beyond $10^{7}$ loading cycles under a relatively low cyclic stress below conventional fatigue limit [1-4]. This is the new research topic of very-high-cycle fatigue (VHCF) that receives increasing research attentions due to not only engineering requirements but also scientific interests [5-10]. The key aspect of the scientific significance is to understand the mechanism of crack initiation and early growth for VHCF, which is basically different from that for lowcycle fatigue (LCF) and high-cycle fatigue (HCF). For LCF and most of HCF cases, the fatigue failure is basically initiated by persistent slip bands from the surface of metallic materials.

For high-strength steels as an instance, the process of VHCF is commonly caused by subsurface or interior crack initiation with the morphology of so-called fish-eye (FiE) containing a rough region of fine-granular-area (FGA) surrounding an inclusion or other defect as crack origin [11-15]. FGA is also called optical dark area (ODA) [11] or granular bright facet (GBF) [16]. Although the size of FiE is just hundreds of microns and that of FGA is only tens of microns, the region of FGA, as crack initiation characteristic region, consumes larger than $95 \%$ of total fatigue life $[17,18]$. To reveal the formation mechanism of this crack initiation characteristic region is extremely essential for understanding the unique

\footnotetext{
* Corresponding author. Tel.: +86 1082543966.

E-mail address: hongys@imech.ac.cn (Y. Hong).
}

behavior of VHCF and predicting the fatigue life of VHCF for high-strength steels. Several mechanisms have been proposed for this aspect, including "hydrogen assisted crack growth" [11,19], "decohesion of spherical carbide" [20], and "formation and debonding of fine granular layer" $[2,21]$.

For the mechanism of "hydrogen assisted crack growth" [11,19], it was stated that the formation of FGA was assisted by the locally concentrated hydrogen. The existence of hydrogen trapped by an inclusion induced the discrete crack growth at a very slow rate during crack initiation and produced a rough fracture surface. When the size of FGA reached the critical value, crack growth occurred without the assistance of hydrogen.

For the mechanism of "decohesion of spherical carbide" [20], it was proposed that the formation of FGA was due to the existence of spherical carbides and their decohesions from the matrix to cause crack initiation in the vicinity of an inclusion. The coalesced crack was along the boundary between spherical carbides and the matrix with the generated roughness to form an FGA region. After the formation of a certain size for FGA, the crack propagation was independent of the spherical carbide decohesion.

For the mechanism of "formation and debonding of fine granular layer" [2,21], it was regarded that FGA was caused by the debonding of the fine granular layer and the matrix to form the rough morphology, and the fine granular layer was generated (before crack initiation) by the intensive polygonization in the vicinity of an inclusion during the long sequence of cyclic loading. It was supposed that when a penny-shape crack of FGA was formed 
(a)

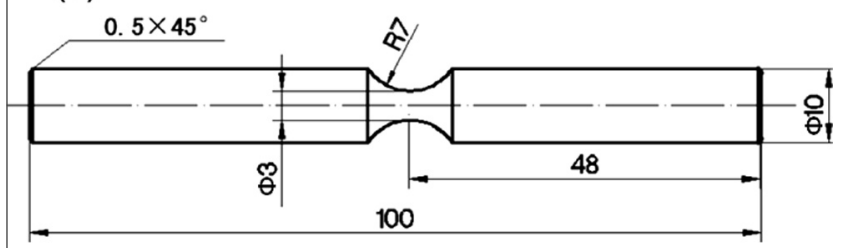

(b)
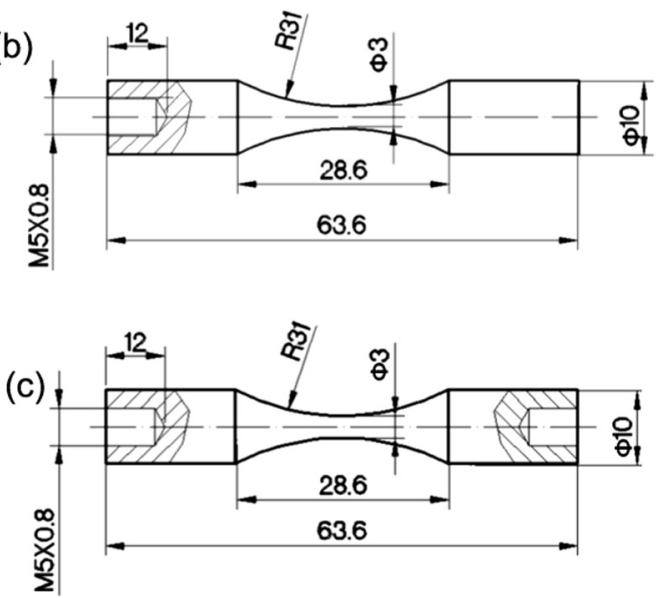

Fig. 1. Three types of specimens used in fatigue testing: (a) for rotary bending, (b) for ultrasonic axial cycling without mean stress, and (c) for ultrasonic axial cycling with superimposed mean stress (dimensions in $\mathrm{mm}$ ).

around the inclusion, the size of FGA was terminated and the crack growth tended to Paris crack regime.

In 2012, an investigation by Grad et al. [22] reported that an average grain size of about $70 \mathrm{~nm}$ was observed in the FGA layer for a high-strength steel and proposed the FGA formation mechanism of "local grain refinement at the crack tip". In fact, this model is very similar to the model of "formation and debonding of fine granular layer" by Sakai [2]. It should be noticed that the model by Sakai [2] and later by Grad et al. [22] stated that the fine grain layer is produced before crack formation or at the head of crack tip. A very recent publication by Chai et al. [23] presented that the occurrence of cyclic localized plastic deformation during VHCF near the subsurface defect leads to the formation of fine granular layer.

One may notice that each of the above proposed mechanisms could explain an individual experimental phenomenon, but every one of them encountered difficulties in the explanation of more general cases. The following lists some examples.

For the cases of VHCF of medium-carbon structural steels, fatigue cracks are initiated from the interior of specimen with FiE fracture mode but without FGA morphology, and for the cases of VHCF of high-strength steels at different stress ratios, crack interior initiation is with FiE but without FGA at positive stress ratio conditions. For example, in the case of VHCF for a medium-carbon structural steel tested by rotary bending $(52.5 \mathrm{~Hz})$ in laboratory air with the stress ratio of $R=-1$, fatigue crack initiated from the subsurface or the interior of specimen with FiE pattern but without FGA morphology [24]. A similar case is the VHCF for a mediumcarbon structural steel tested by ultrasonic axial cycling $(21 \mathrm{kHz})$ in laboratory air with the stress ratios of $R=-1$ and $R=0$, for which cracks nucleated at non-metallic inclusions in the interior of specimen with FiE morphology but FGA was not visible on fracture surfaces [25]. Another interesting case [26] is that, for a high-carbon bearing steel with axial cycling $(50 \mathrm{~Hz})$ under the stress ratios of $R=0$ and $R=0.5$, fatigue cracks initiated from the interior of

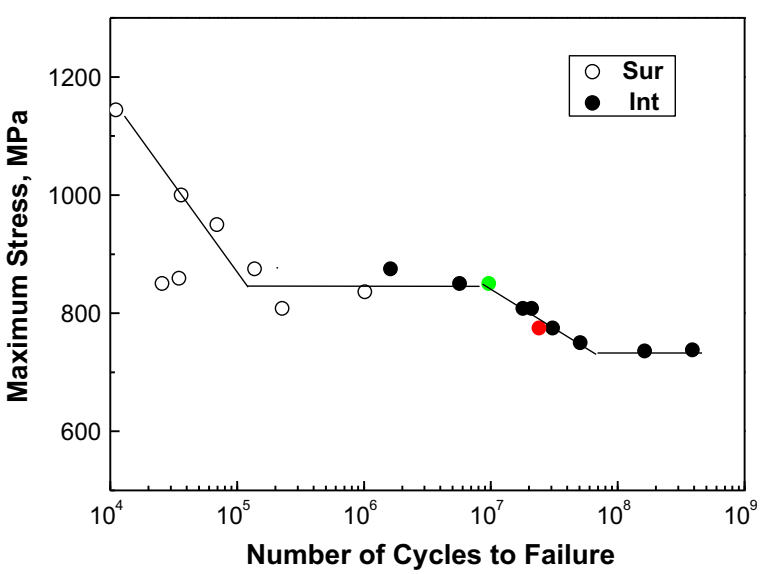

Fig. 2. S-N data of material A, showing fatigue strength decreases with the increase of loading cycles, and for fatigue life $\left(N_{\mathrm{f}}\right)$ beyond $2 \times 10^{6}$ cycles, failure caused by crack initiation at the interior of specimen. Sur: crack initiation at surface, Int: crack initiation at interior, red point: specimen A1, green point: specimen A2.

specimen with FiE pattern and FGA morphology at the failure cycles of $6.22 \times 10^{7}$ at $R=0$, whereas the initiation region was with FiE but without FGA morphology at the failure cycles of $2.57 \times 10^{5}$ at $R=0$. A recently reported case [27] of VHCF for a martensitic $12 \%$ Cr steel $(0.117 \% \mathrm{C})$, for which the specimens were tested by axial cycling $(20 \mathrm{kHz})$ in laboratory air at the stress ratios from -1 to 0.7 , showed that FGA was observed in the specimens at $R=-1$ but never found in the specimens fatigued at $R=0.1,0.5$ and 0.7 . It is obvious that the presence or the absence of FGA in the crack initiation process of VHCF in above cases cannot be explained or reconciled by the existed proposed mechanisms. It should be emphasized that, FGA is a characteristic region at crack initiation for VHCF of high-strength steels and its size is the characteristic dimension for crack initiation, which is responsible for a majority part of larger than $95 \%$ of total fatigue life $[17,18]$. Therefore the revelation of the formation mechanism for the crack initiation region of FGA is a key point not only for understanding the physical process of VHCF crack initiation but also for predicting the fatigue life containing VHCF regime.

Thus one sees an unclear issue in the understanding of the formation mechanism for the characteristic region of crack initiation for VHCF of high-strength steels. What is the microscopic nature of FGA? What is the real formation mechanism of this characteristic area? The present paper is aiming at the answer to these two challenging questions.

For this purpose, we carefully examined the micro-morphology of crack profile at FGA and FiE regions for a high-strength steel by transmission electron microscopy (TEM) and scanning electron microscopy (SEM) with the samples prepared by ion beam cross section polishing (IBP) and focused ion beam (FIB) cutting, showing the microstructure features of FGA and FiE regions together with reflected electron selected area diffraction (SAD) patterns. The observations revealed that the microscopic nature of FGA is a thin layer of nano-sized grains. Based on this unique revelation, we proposed that the formation mechanism of crack initiation characteristic region of FGA is due to the numerous cyclic pressing (NCP) at originated crack surfaces simultaneously with crack growing, which causes the grain refinement at the wake of originated crack. Then a second set investigation was carried out for a similar highstrength steel with ultrasonic axial cycling at different stress ratios of $R=-1,-0.5,0.1$ and 0.3 . The results showed that the test cases of negative stress ratios exhibit the prevalence of nanograin layer in the FGA region and this tendency vanishes for the test cases of positive stress ratios, which is a verification of the proposed NCP 

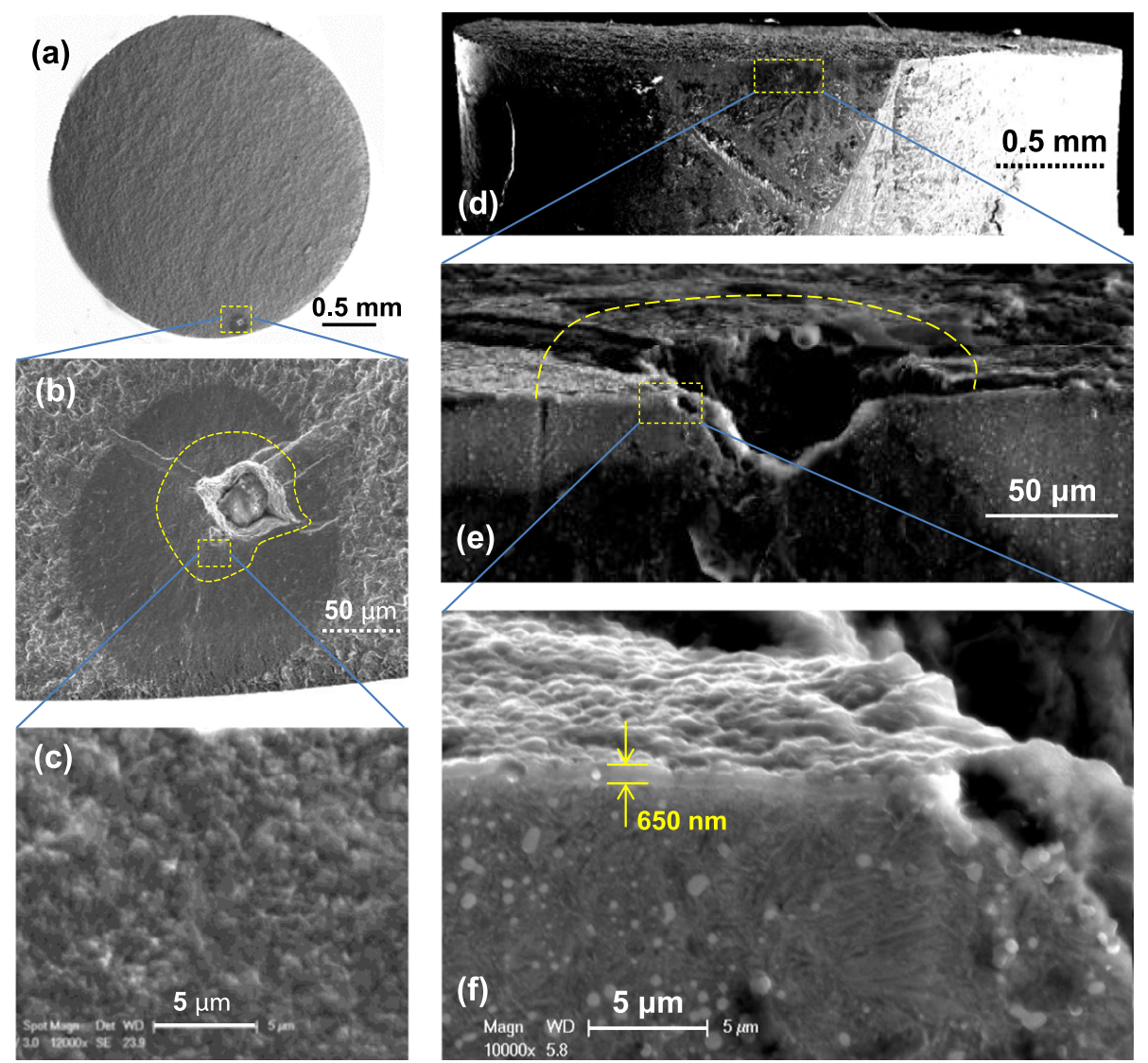

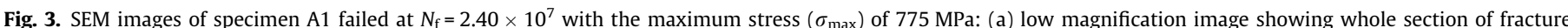

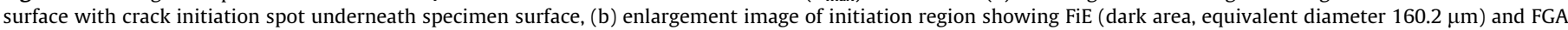

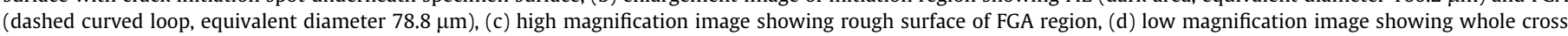

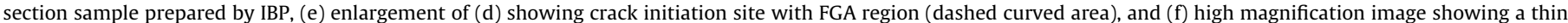
layer microstructure of $650 \mathrm{~nm}$ in thickness in FGA region.

model of FGA formation. Our findings also suggested that numerous cyclic pressing with appropriate conditions may produce thin nano-sized grain layer of metallic materials.

\section{Test materials and experimental methods}

Two high-strength steels were used for two set experiments in this investigation. The material for the first set experiment is a high-strength steel with the chemical compositions (wt.\%) of: 1.06 C, $1.04 \mathrm{Cr}, 0.88 \mathrm{Mn}, 0.34 \mathrm{Si}, 0.027 \mathrm{P}, 0.005 \mathrm{~S}$ and Fe balance, which is named material $\mathrm{A}$ in this investigation. The specimens of material A were austenitized at $845^{\circ} \mathrm{C}$ for $2 \mathrm{~h}$ in vacuum, oilquenched and tempered for $2 \mathrm{~h}$ in vacuum at $180^{\circ} \mathrm{C}$. The tensile strength of material A was $1849 \mathrm{MPa}$ from the tensile tests on four cylindrical specimens with the diameter of $5 \mathrm{~mm}$ in gage section, and the micro-hardness was $753 \mathrm{Hv}\left(\mathrm{kgf} / \mathrm{mm}^{2}\right)$ measured by a micro-hardness tester at a load of $0.5 \mathrm{~N}$ with the load holding time of $15 \mathrm{~s}$.

The material for the second set experiment is a similar highstrength steel with the chemical compositions (wt.\%) of: $1.04 \mathrm{C}$, 1.51 Cr, 0.29 Mn, 0.24 Si, 0.0058 P, 0.0030 S and Fe balance, which is named material $\mathrm{B}$ in this investigation. The specimens of material B were austenitized at $845^{\circ} \mathrm{C}$ for $1 \mathrm{~h}$ in vacuum, oilquenched and tempered for $2 \mathrm{~h}$ in vacuum at $180^{\circ} \mathrm{C}$. The tensile strength of material B was $1896 \mathrm{MPa}$ from the tensile testing on 5 cylindrical specimens with the diameter of $6 \mathrm{~mm}$ in gage section, and the micro-hardness was $760 \mathrm{Hv}\left(\mathrm{kgf} / \mathrm{mm}^{2}\right)$ measured by a micro-hardness tester at a load of $0.5 \mathrm{~N}$ with the load holding time of $15 \mathrm{~s}$.

For the first set experiment, hour-glass shape specimens were used in fatigue testing, which were machined with the minimum diameter of $3 \mathrm{~mm}$ and the round notch radius of $7 \mathrm{~mm}$, as shown in Fig. 1a. The specimen geometry is designed to fit the rotating testing. The right end of specimen (Fig. 1a) is clamped to a gripping end of rotary machine and the left end is loaded with applied weight. The stress concentration factor for the specimen is simply calculated as 1.06 . Such specimens were subjected to rotary bending by a testing machine with the rotating speed of $3150 \mathrm{rpm}$ (frequency $52.5 \mathrm{~Hz}$ ) and the stress ratio is -1 .

For the second set experiment, two types of hour-glass shape specimens were used in fatigue testing, which were machined with the minimum diameter of $3 \mathrm{~mm}$ and the round notch radius of $31 \mathrm{~mm}$, as shown in Fig. 1b and c. The specimen geometry is designed based on the resonance consideration to ensure that the natural frequency of specimen matches the vibration frequency of ultrasonic testing machine. The specimen shown in Fig. 1b is for the fatigue testing without mean stress $(R=-1)$, for which the left end is mounted to ultrasonic machine and the right end is free. The specimen shown in Fig. 1c is for the fatigue testing with superimposed mean stress $(R \neq-1)$, for which the left end is mounted to ultrasonic machine and the right end is connected to the clamping end of superimposed tensile device. Such specimens (Fig. 1b and c) were loaded by axial cycling at the stress ratios of $R=-1,-0.5,0.1$ and 0.3 via an ultrasonic machine running at the resonance frequency of $20 \mathrm{kHz}$. The ultrasonic machine was installed in a 

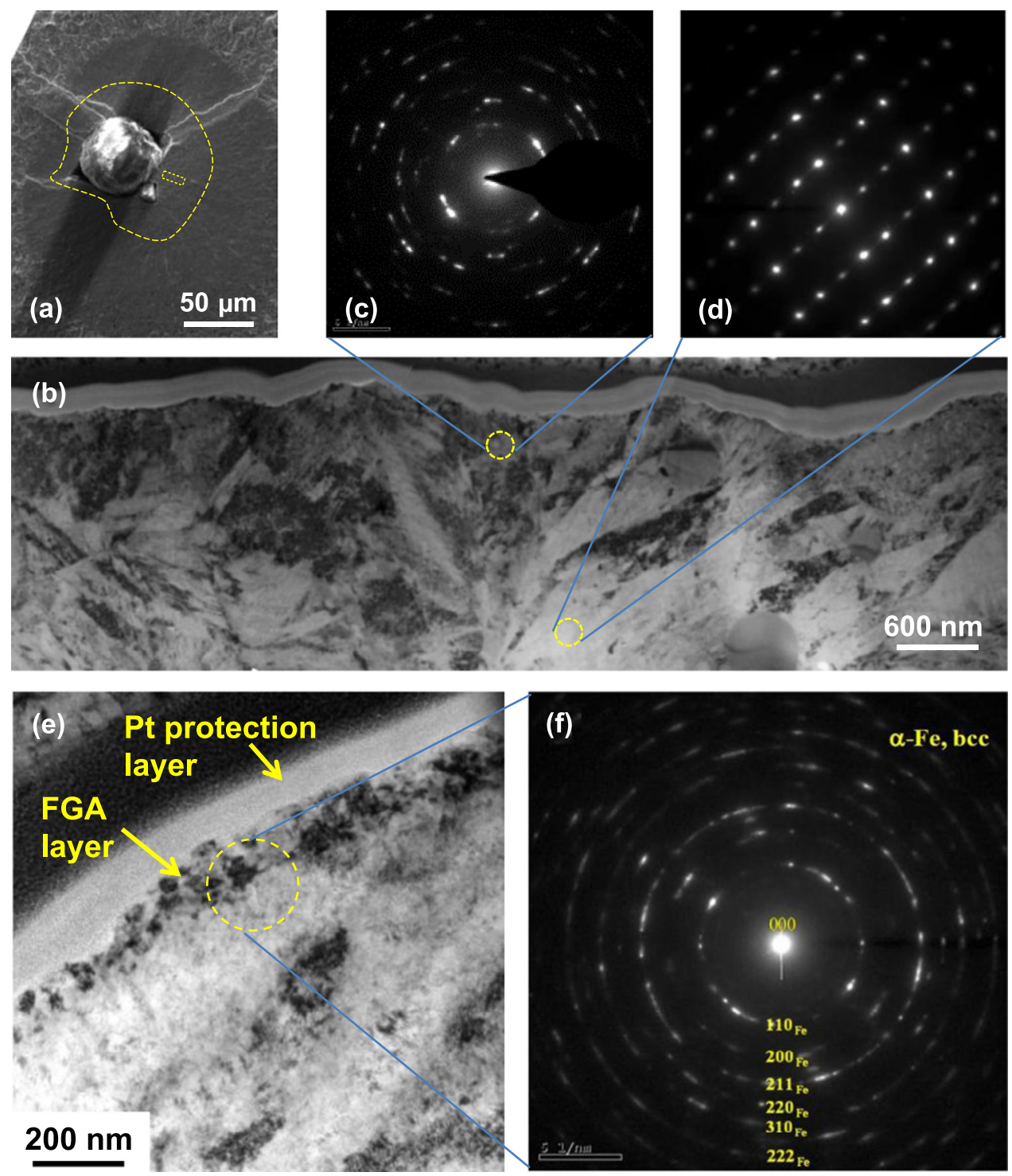

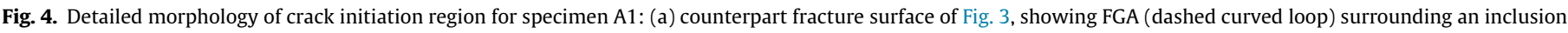

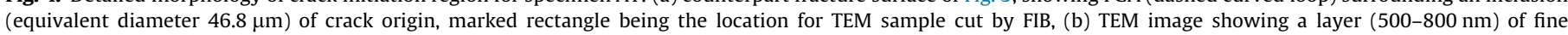

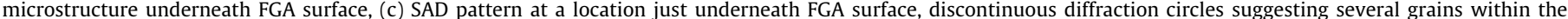

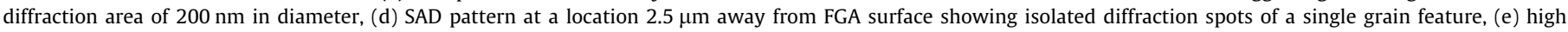

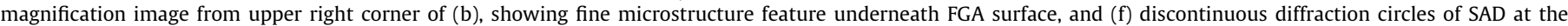
location underneath FGA surface with calibrated indexes well matching the standard values of $\alpha$-Fe (bcc lattice).

conventional tensile machine (capacity $20 \mathrm{kN}$ ) to enable the superimposition of an amount of mean stress (supplied by the tensile machine) to the applied cyclic stress (generated by the ultrasonic machine) of every test case except for those of $R=-1$. Compressed air system was used to cool specimen surface during cyclic loading to eliminate temperature increase.

Crack initiation regions of fractured specimens were observed with SEM, for which the morphologies from a pair of fracture surfaces and the cross-section of crack initiation region were examined. The cross-section sample was prepared by IBP and was etched before observation. Furthermore the profile samples, with the size of length $10 \mu \mathrm{m}$, width (depth) $5 \mu \mathrm{m}$ and thickness $80 \mathrm{~nm}$, were sliced from the crack initiation region on fracture surfaces, which were cut by FIB with the fracture surface protected by a thin coating layer of platinum (Pt). The crack initiation regions of such profile samples were carefully examined via TEM equipped with the detection unit of SAD with the diffraction area of
$200 \mathrm{~nm}$ in diameter. The obtained SAD patterns were calibrated and indexed.

\section{Detailed characterization of FGA and NCP model: results and discussion of first set experiment}

Fig. 2 is the fatigue testing results for the first set experiment, showing the step-wise $\mathrm{S}-\mathrm{N}$ curve with small scattering for material A subjected to rotary bending at the stress ratio of $R=-1$. The fatigue strength decreases with the increase of loading cycles, and for fatigue life $\left(N_{\mathrm{f}}\right)$ beyond $2 \times 10^{6}$ loading cycles, the fatigue failure was caused by crack initiation at the interior of specimen. The slope for the data of crack initiation from the surface of specimen is larger than that for crack initiation from the interior of specimen.

As an example, Fig. 3 presents the SEM images showing the morphology of crack initiation at the interior of specimen from 

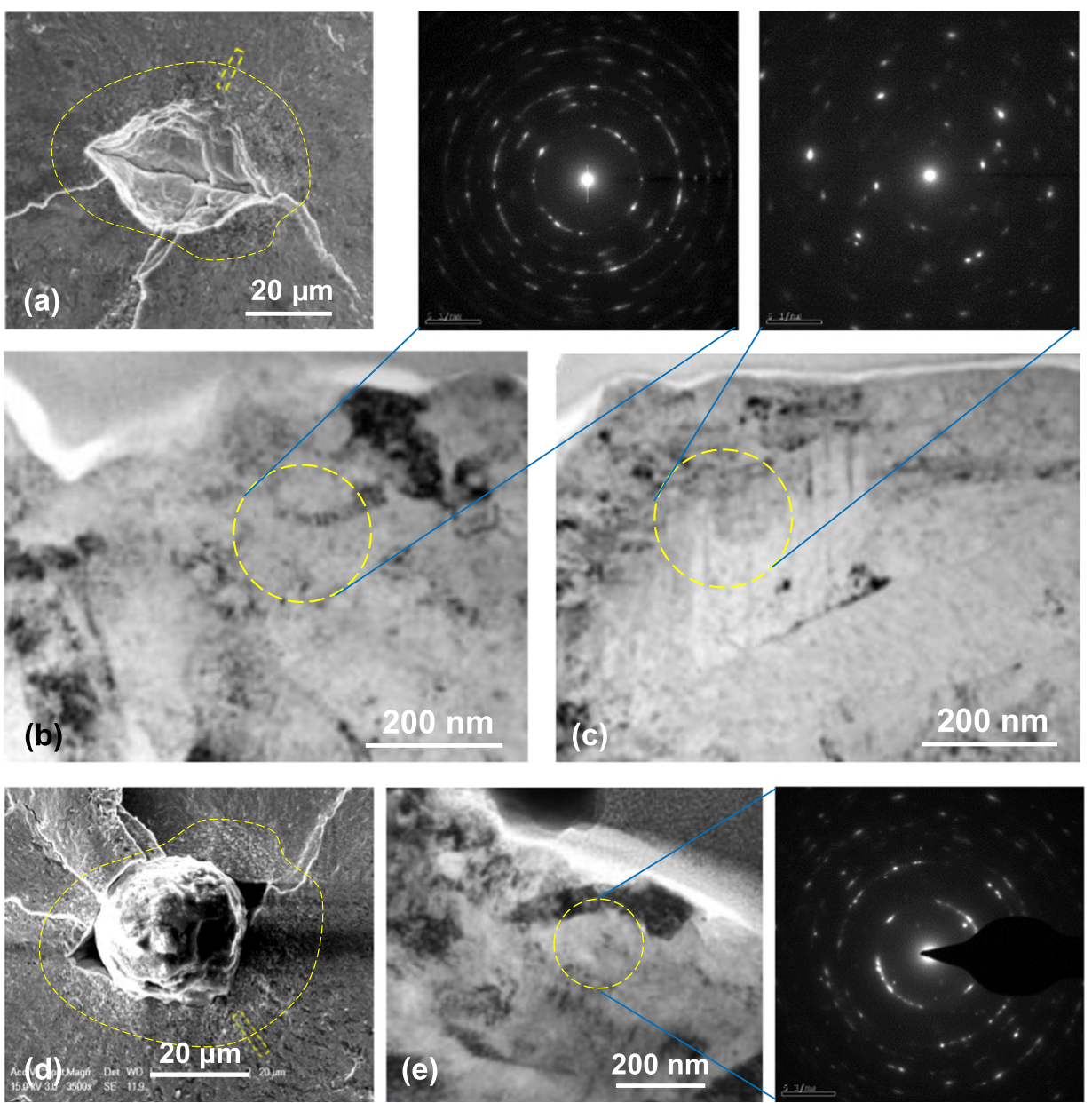

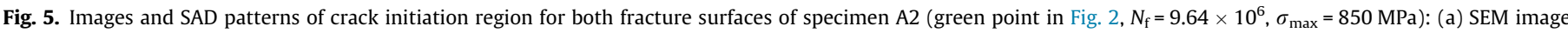

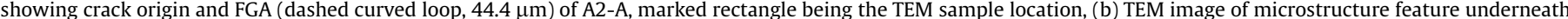

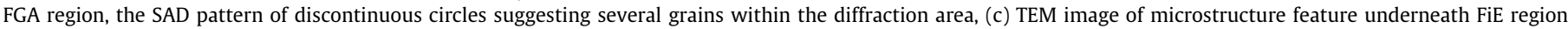

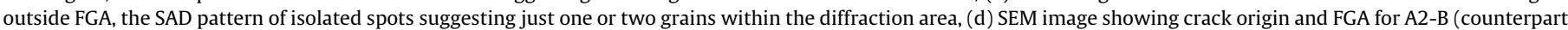

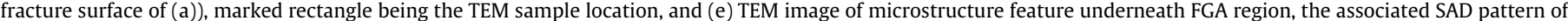

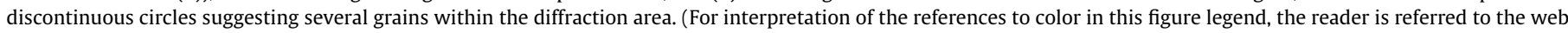
version of this article.)

low magnification (Fig. 3a) to high magnification (Fig. 3c) for specimen A1 failed at $N_{\mathrm{f}}=2.40 \times 10^{7}$ with the maximum stress $\left(\sigma_{\max }\right)$ of $775 \mathrm{MPa}$ (red point in Fig. 2). It is seen from Fig. 3b that the region of FiE (dark area, equivalent diameter $160.2 \mu \mathrm{m}$ ) envelops an FGA (dashed area, equivalent diameter $78.8 \mu \mathrm{m}$ ) containing a crack origin from an inclusion, and the FGA is of rough surface under a high magnification (Fig. 3c). To further examine this FGA region, we observed the cross-section sample (Fig. 3d-f) from the same specimen A1 by SEM and the observations showed that the FGA is a layer of fine microstructure with the average thickness of $650 \mathrm{~nm}$ (Fig. 3f).

In order to identify the microscopic nature of this fine microstructure layer, we performed TEM observation with SAD examination on the carefully prepared profile sample cut by FIB. To correlate the observations with Fig. 3, we used the counterpart fracture surface from the same specimen A1 (Fig. 3b), i.e. Fig. 4a is this counterpart image which shows the FiE region with the FGA (dashed curved loop) surrounding the inclusion of crack origin. The EDS (energy dispersive spectroscopy) examinations for the chemical compositions of the inclusion in Fig. 4a (also in Fig. 5d) show that the nonmetallic inclusion consists of $\mathrm{Al}_{2} \mathrm{O}_{3}, \mathrm{CaO}, \mathrm{MgO}$ and $\mathrm{SiO}_{2}$ [28]. An FIB sample was cut from the FGA region (marked rectangle in Fig. $4 \mathrm{a}$ ) and Fig. $4 \mathrm{~b}$ is the TEM image of this FIB sample showing a narrow band of about $500-800 \mathrm{~nm}$ in width underneath the surface of the FGA region, which is a kind of fine microstructure as the transition product of tempered martensite. Away from this narrow band, the microstructure is the feature of ordinary coarse tempered martensite. The SAD pattern of Fig. 4c shows the discontinuous diffraction circles for the location underneath FGA surface, suggesting that (by the diffraction principle [29]) several grains exist within the diffraction area of $200 \mathrm{~nm}$ in diameter. Whereas away from the narrow band, the SAD image of Fig. $4 \mathrm{~d}$ is a pattern of isolated spots, which is a normal diffraction of a single grain (by the diffraction principle [29]). Furthermore, Fig. 4e is the high magnification image of the narrow band and the associated SAD pattern of Fig. $4 \mathrm{f}$ presents discontinuous circles with calibrated indexes well corresponding to the standard diffraction pattern of iron [29]. From such TEM images as Fig. 4e, the average equivalent grain diameter was measured as $48 \mathrm{~nm}$.

To confirm this breakthrough revelation, we selected another specimen A2, failed at $N_{\mathrm{f}}=9.64 \times 10^{6}$ with $\sigma_{\max }=850 \mathrm{MPa}$ (green point in Fig. 2), for the examination on the same location for both sides of fracture surface of the crack initiation region (Fig. 5a taken from sample A2-A and Fig. 5d taken from sample A2-B). The location for FIB profile sample, which is marked in both Fig. 5a and d, is just on the FGA boundary to contain half of the FGA region and 

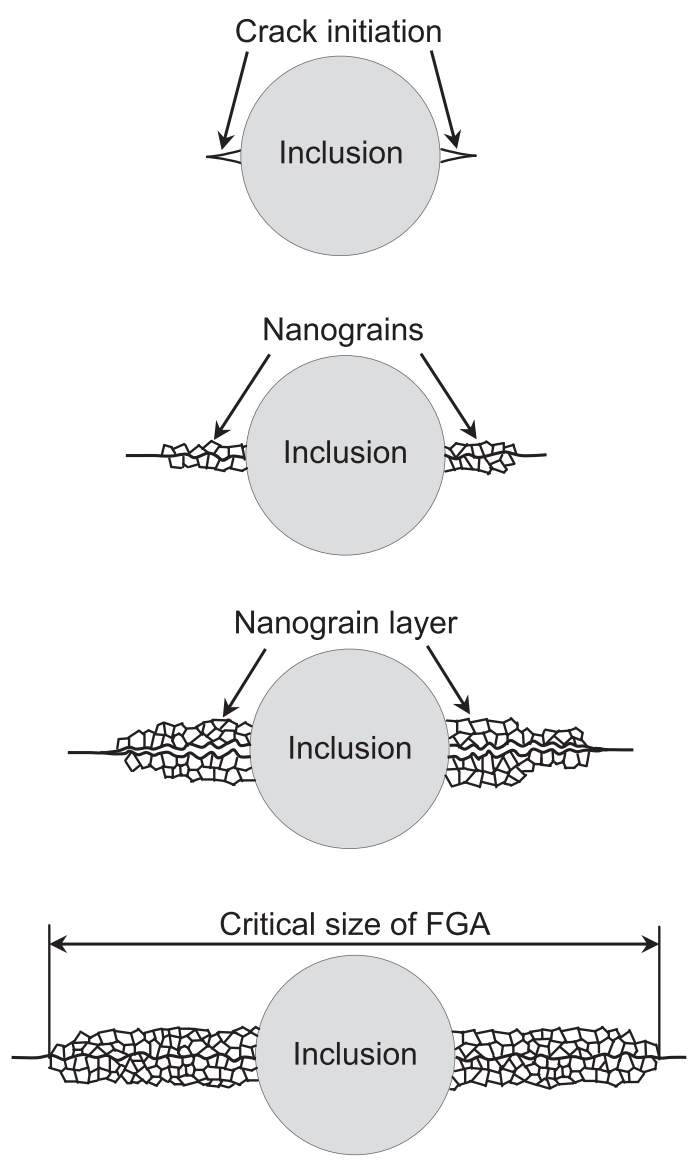

(d) Numerous Cyclic Pressing process terminated at transient

point to form critical size of FGA.

(a) Crack initiation at interface between inclusion and matrix.

(b) Formation of nanograins at crack wake by repeated pressing between crack surfaces due to cyclic loading, associated with crack closure and residual stress relaxation.

(c) Presence of a nanograin layer in previous crack surfaces with rough morphology after million loading cycles simultaneously with nanograin formation in new crack surfaces.

Fig. 6. Schematic drawing and brief description of Numerous Cyclic Pressing (NCP) model.

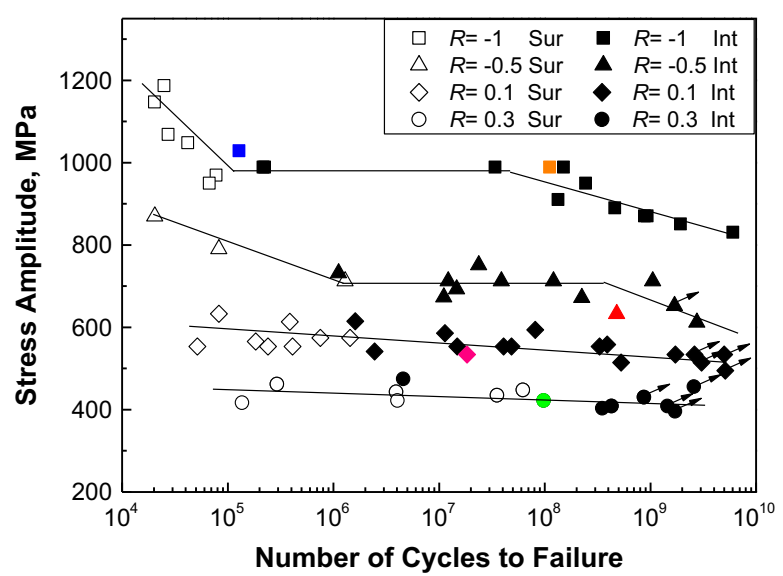

Fig. 7. S-N data of material $\mathrm{B}$ at stress ratios of $R=-1,-0.5,0.1$ and 0.3 , in terms of applied stress amplitude $\left(\sigma_{\mathrm{a}}\right)$ versus fatigue life, showing that fatigue strength is the highest for the case of $R=-1$ and the lowest for the case of $R=0.3$. For the cases of $R=-1,-0.5$ and 0.1 , fatigue crack initiated from the interior of specimen after $10^{6}$ cycles of loading, and for the case of $R=0.3$, a few specimens failed due to crack initiation at surface between $10^{6}$ and $10^{8}$ cycles of loading. Symbols with arrow: run out specimens without broken, Sur: crack initiation at surface, Int: crack initiation at interior.

another half of the FiE region outside FGA. The TEM observations on A2-A showed that in the FGA region, discontinuous diffraction circles prevail (Fig. 5b), suggesting a number of grains within the diffraction area of $200 \mathrm{~nm}$ in diameter, whereas in the FiE region outside FGA, isolated diffraction spots present (Fig. 5c), indicating just one or two grains in the diffraction area. For the opposite side 

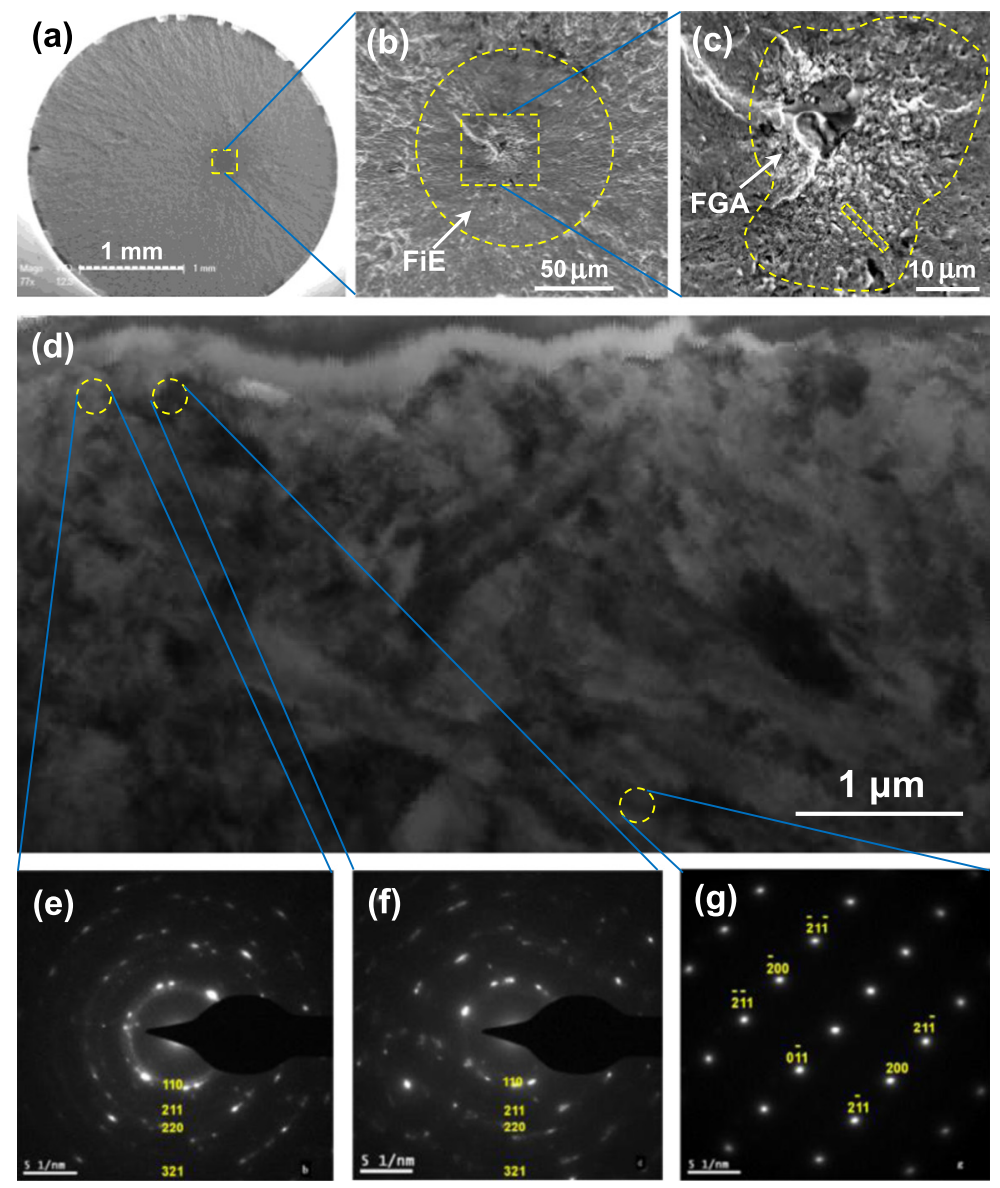

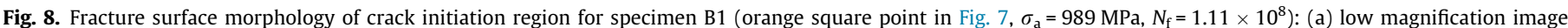

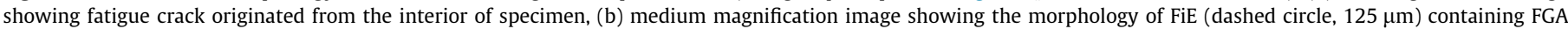

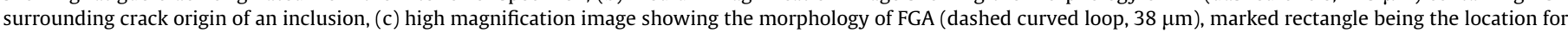

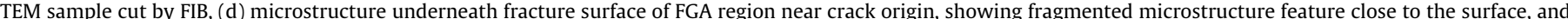

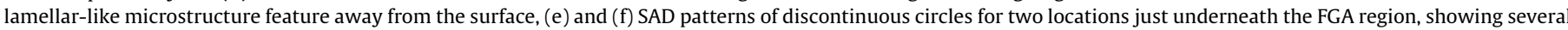

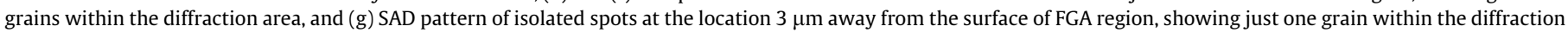
area.

where $K_{\mathrm{I} \text { max }}$ is the maximum value of stress intensity factor, $\sigma_{0}$ is the maximum tensile stress, and $\sqrt{\mathrm{area}_{\mathrm{i}}}$ is the value of interior crack area. Thus, this transient condition is postulated as Eq. (2)

$a_{\mathrm{FGA}}=Y^{\prime}\left(\frac{\Delta K_{\mathrm{FGA}}}{\sigma_{\max }}\right)^{2}$,

where $a_{\mathrm{FGA}}$ is FGA size, $\Delta K_{\mathrm{FGA}}$ is stress intensity factor range for FGA, $\sigma_{\max }$ is applied maximum stress and $Y^{\prime}$ is crack shape parameter that takes the same value as Eq. (1) of $4 / \pi$. Consider that the critical state for the termination of FGA is the plastic zone size of an originated crack equal to the characteristic microstructure dimension [35,36], so that to give the following equation [35]

$\Delta K_{\mathrm{FGA}}=\mu(6 \pi b)^{1 / 2}$,

with $\mu$ being the shear modulus and $b$ the magnitude of Burgers vector of material. Thus we have

$a_{\mathrm{FGA}}=Y b\left(\frac{\mu}{\sigma_{\max }}\right)^{2}$,

with $Y$ being $6 \pi Y^{\prime}=24$ for the present case. Eq. (4) implies that for a given material, the critical size of FGA just depends on the applied maximum stress.

In fact, the process of NCP may be regarded as a new approach of severe plastic deformation to fabricate nanostructured metals and alloys, which could be similar to other approaches [37,38]. Thus, the NCP model also provides a new concept for creating new approach to produce metallic thin-film with nano-sized microstructure.

In our proposed NCP model, the presence of crack closure, namely the contact of the two fracture surfaces of an originated crack, plays an essential role in the formation of nanograins, and the formation of nanograins needs a large number of cyclic contacting. Thus, one comes up with two inferences based on the proposed NCP model: (1) for the case of negative stress ratio condition, if the number of loading cycles is insufficient, the formation of nanograins at the originated crack wake will be incomplete, and (2) for the cyclic loading at positive stress ratio condition with less crack closure effect, the NCP process will be less prevalence and the formation of nanograins at the originated crack wake will be less possible. Therefore, we carry out the second set experiment to verify these two inferences.

\section{Stress ratio effect and NCP model verification: results and discussion of second set experiment}

In the second set experiment, fatigue tests on another highstrength steel similar to that of the first set experiment were performed via ultrasonic axial cycling with the frequency of $20 \mathrm{kHz}$ and the stress ratio was controlled at $R=-1,-0.5,0.1$ and 0.3 , 

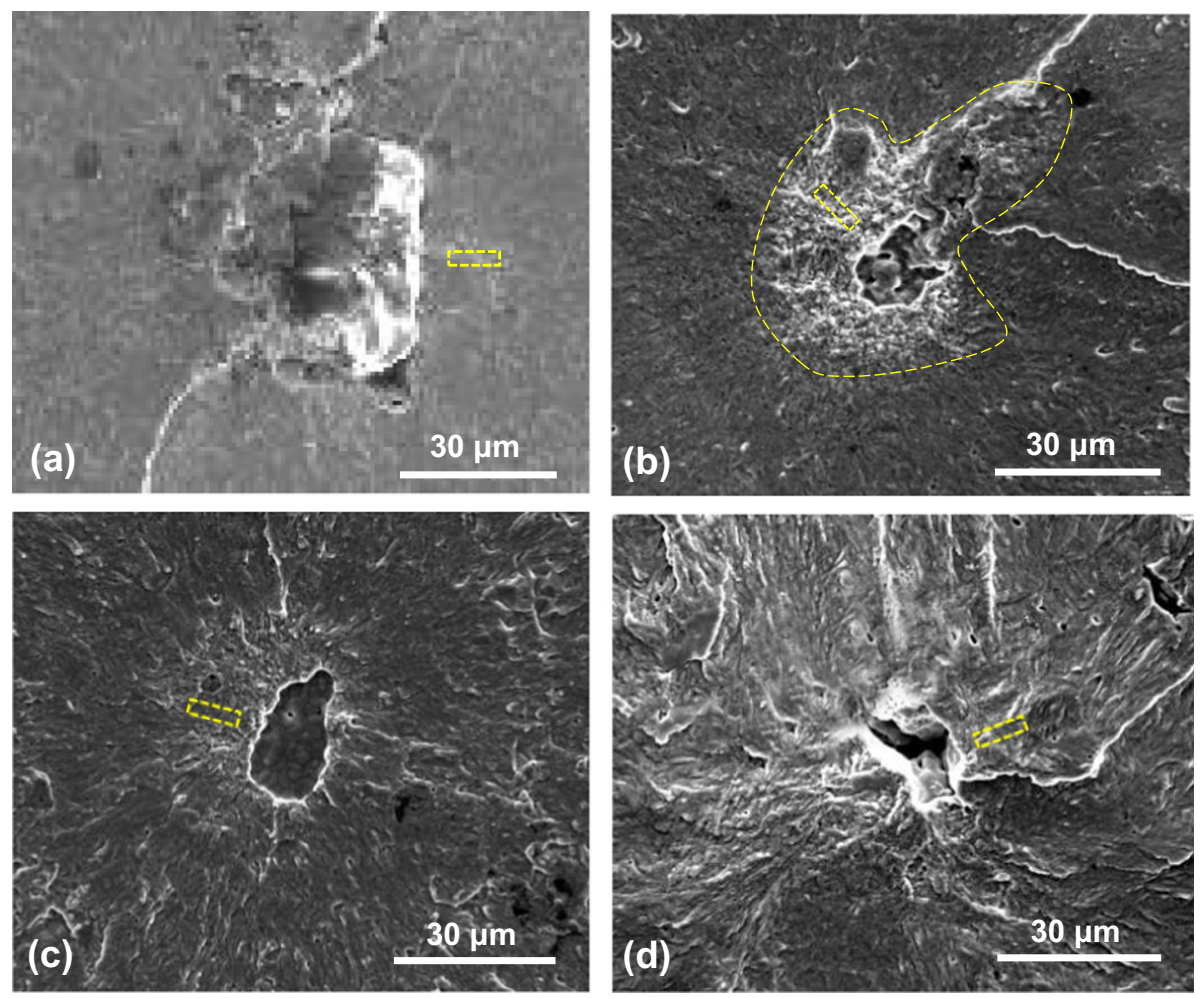

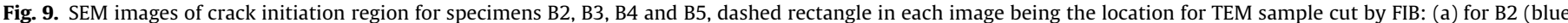

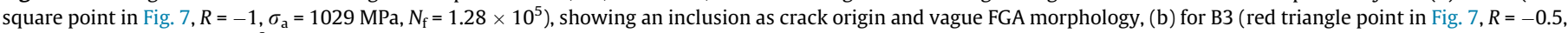

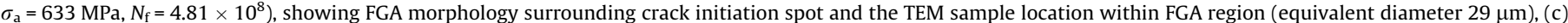

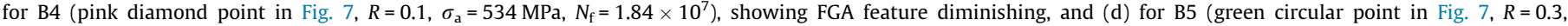

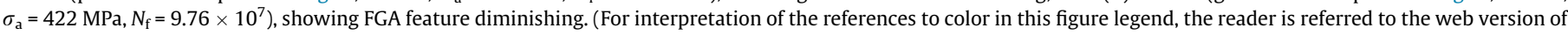
this article.)

respectively. Fig. 7 is the fatigue testing results, showing the $\mathrm{S}-\mathrm{N}$ data, with small scattering, in terms of applied stress amplitude $\left(\sigma_{\mathrm{a}}\right)$ versus fatigue life for the stress ratios of $R=-1,-0.5,0.1$ and 0.3. It is seen that fatigue strength is the highest for the case of $R=-1$ and the lowest for the case of $R=0.3$. For the cases of $R=-1,-0.5$ and 0.1 , fatigue crack initiated from the interior of specimen after $10^{6}$ cycles of loading, and for the case of $R=0.3$, a few specimens failed with crack initiation at surface between $10^{6}$ and $10^{8}$ cycles of loading. For the case of $R=-1$, the $\mathrm{S}-\mathrm{N}$ curve is of step-wise trend with the slope for the data of crack initiation from the surface of specimen being larger than that for the crack initiation from the interior of specimen. For the case of $R=-0.5$, the S-N curve is still of step-wise trend with the slope for surface crack initiation data being almost the same as that for interior crack initiation data. For the cases of $R=0.1$ and 0.3 , the $\mathrm{S}-\mathrm{N}$ curves are single lines with almost the same slope.

We selected 5 fatigue failed specimens for examination: (i) two from $R=-1$ with one failed in VHCF regime (B1, orange square point in Fig. $\left.7, \sigma_{\mathrm{a}}=989 \mathrm{MPa}, N_{\mathrm{f}}=1.11 \times 10^{8}\right)$, and the second one failed at relatively low loading cycles (B2, blue square point in Fig. 7, $\sigma_{\mathrm{a}}=1029 \mathrm{MPa}, N_{\mathrm{f}}=1.28 \times 10^{5}$ ), and (ii) the rest three ones (B3, B4 and B5) failed in VHCF regime from $R=-0.5,0.1$ and 0.3 , respectively.

For the case of $R=-1$ and failed in VHCF regime (B1), the images of FGA and FiE with SAD patterns are shown in Fig. 8. The EDS examination shows that this non-metallic inclusion contains the contents of $\mathrm{Ti}(70 \%), \mathrm{V}(4.4 \%)$ and $\mathrm{Cr}(10.8 \%)$. It is seen from Fig. $8 \mathrm{a}-\mathrm{c}$ that fatigue crack initiated from the interior of specimen with the clear morphology of FiE and FGA. Fig. 8d-g are FIB sample observations with associated SAD examinations on the
FGA region which is marked (rectangle) in Fig. 8c. It is observed that a layer of fragmented fine microstructure appears underneath the FGA surface (Fig. 8d) with the SAD patterns being discontinuous circles (Fig. 8e and f), implying a number of grains within the diffraction area of $200 \mathrm{~nm}$, whereas in the location away from the FGA surface, lamellar-like microstructure (Fig. 8d) presents with the SAD image being a clear pattern of isolated spots (Fig. 8g), implying just one grain in the diffraction area. These results are consistent with those of first set experiment of A1 (Figs. 3 and 4) and A2 (Fig. 5). All these observations confirm that for the case of $R=-1$ failed in VHCF regime, the FGA region is a layer of nanograins.

For the case of $R=-1$ but failed at a relatively small number of loading cycles (the magnitude of $10^{5}$ ), specimen B2 (blue square point in Fig. 7) is such an example which was failed at $N_{\mathrm{f}}=1.28 \times 10^{5}$ with $\sigma_{\mathrm{a}}=1029 \mathrm{MPa}$. The fractography of this specimen (Fig. 9a) shows crack initiated from the interior of specimen but the region of crack initiation was almost without FGA morphology. The EDS result shows that the non-metallic inclusion contains the major elements of $\mathrm{Al}$ and $\mathrm{Ca}$. Fig. 10a shows the microstructure feature of the FIB sample cut from specimen B2 (marked rectangle in Fig. 9a) and the associated SAD patterns detected from the location underneath the fracture surface of crack initiation region (dashed circles in Fig. 10a) show a kind of slightly elongated spots, which is a reflection of texture feature (by the diffraction principle [29]). The evidence of texture-like microstructure in the surface layer of originated crack wake is surprising, which suggests that just a couple of grains (no many) exist with very close crystallographic orientation within the diffraction area (by the diffraction principle [29]). This evidence verifies the first inference that for 

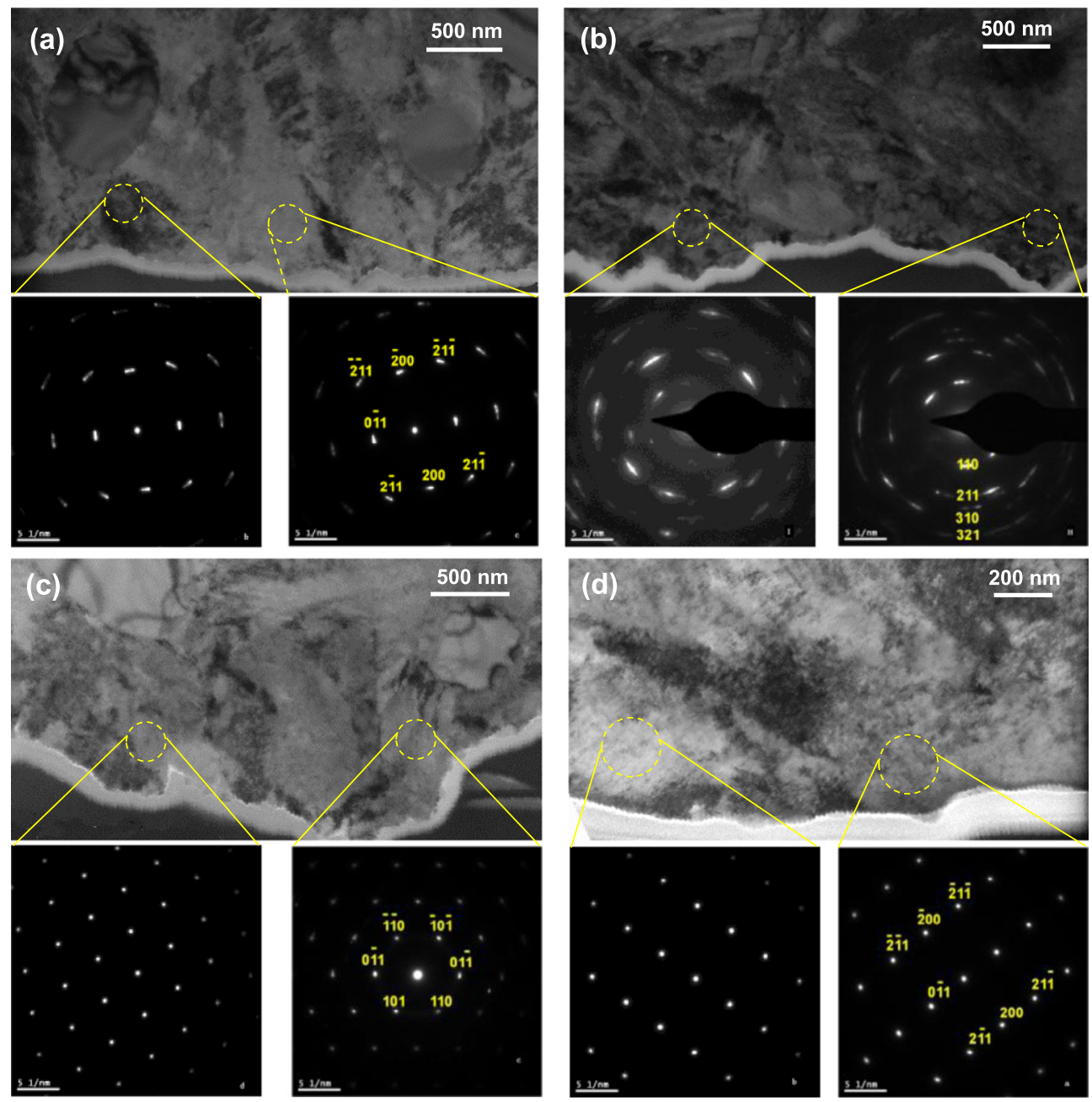

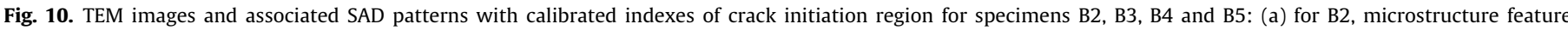

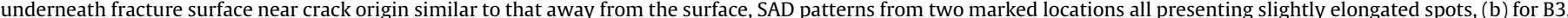

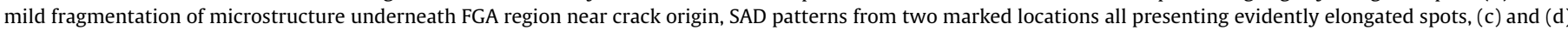

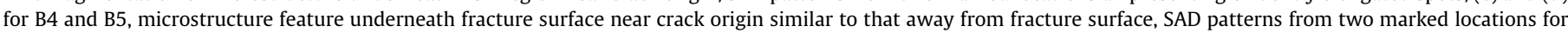
each case all presenting isolated spots.

the case of relatively low cyclic numbers at negative stress ratio, the formation of nanograins in the wake of originated crack is incomplete.

For the case of $R=-0.5$ failed in VHCF regime, specimen B3 (red triangle point in Fig. 7) is an example which was failed at $N_{\mathrm{f}}=4.81 \times 10^{8}$ with $\sigma_{\mathrm{a}}=633 \mathrm{MPa}$. The fractography of this specimen (Fig. 9b) shows that fatigue crack initiated from the interior of specimen and the region of crack initiation was FGA surrounding the crack origin. The EDS result shows that the chemical composition of this crack origin contains the majority of $\mathrm{Fe}$, which suggests that the crack initiation spot is due to the defect of matrix. For the cases of specimens B4 and B5, the EDS examinations also give similar results. Fig. 10b is the TEM image from the FIB sample (marked rectangle in Fig. 9b) cut from the crack initiation region showing a layer of fine grains underneath the FGA surface, and the associated SAD patterns detected from the location underneath fracture surface in the crack initiation region (dashed circles in Fig. 10b) present discontinuous diffraction circles with obviously elongated spots, which is likely a layer of nanograins with close crystallographic orientations (by the diffraction principle [29]). The SAD circles for specimen B3 (Fig. 10b) are not as continuous as those of A1 (Fig. 4c and f), A2 (Fig. 5b and e) and B1 (Fig. 8e and f), but the spots of B3 (Fig. 10b) are much elongated than the case of specimen B2 (Fig. 10a), suggesting that the number of grains within the diffraction area for the case of $R=-0.5$ failed in VHCF regime is less than that for the case of $R=-1$ failed in VHCF regime but it is larger than that for the case of $R=-1$ failed at a relatively small number of loading cycles.

For the case of $R=0.1$, specimens B4 $\left(N_{\mathrm{f}}=1.84 \times 10^{7}, \sigma_{\mathrm{a}}=534\right.$ $\mathrm{MPa}$, pink diamond point in Fig. 7) is an example failed in VHCF regime, and for the case of $R=0.3$, specimen B5 $\left(N_{\mathrm{f}}=9.76 \times 10^{7}\right.$, $\sigma_{\mathrm{a}}=422 \mathrm{MPa}$, green circular point in Fig. 7) is an example failed in VHCF regime; both specimens failed due to fatigue crack initiation from the interior of specimen. Fig. $9 c$ and $d$ are the SEM images of crack initiation region for specimen B4 and specimen $B 5$, respectively. It is seen that for these two cases with positive stress ratios of $R=0.1$ and $R=0.3$, crack initiation region is almost without FGA morphology. Fig. 10c and d are TEM images for B4 and $B 5$, respectively, from the FIB samples cut from the crack initiation region, and the associated SAD patterns from the location underneath fracture surface in the crack initiation region (dashed circles in Fig. 10c and d) of these two cases show the explicit isolated spots, indicating that for both cases only a single grain (by the diffraction principle [29]) presents in the diffraction area at the 
wake of originated crack. This is a distinct evidence to verify the second inference that for positive stress ratio conditions, the formation of nanograins in the wake of originated crack is less possible due to the less crack closure effect and the less contacting action between two crack surfaces.

It should be emphasized that the formation mechanism of crack initiation in VHCF regime investigated in this paper is for the cases of smooth (or small curvature notched) specimens. There is not an evident stress concentration on the specimen surface of such specimens and fatigue crack initiation shifts from the surface to the interior of specimen, which is a unique feature for VHCF of highstrength materials. For the cases of large curvature notched specimens $[39,40]$, the stress concentration on the notch root is severe, which leads to crack initiation and growth inevitably from the notch root including in VHCF circumstances. The notch effect in VHCF regime is an interesting topic which is our in progress research.

\section{Conclusions}

The conclusions of this investigation for high-strength steels are drawn as follows:

(1) The microscopic nature of the crack initiation characteristic region of FGA for VHCF is a layer of nanograins with the thickness ranging from $500 \mathrm{~nm}$ to $800 \mathrm{~nm}$ and the nanograin size is of the magnitude of $50 \mathrm{~nm}$. This nanograin layer exists in the both sides of fracture surface of FGA region.

(2) The formation mechanism of the crack initiation characteristic region of FGA is Numerous Cyclic Pressing between the two originated crack surfaces associated with crack closure and the proposed NCP model is able to explain the formation of FGA region.

(3) Nanograin layer of FGA region prevails for the cases of negative stress ratios but nonograins do not present for the cases of positive stress ratios and for the case of negative stress ratio with relative small loading cycles. This verifies the proposed NCP model.

(4) The proposed NCP model provides a key basis not only for understanding the crack initiation process for VHCF but also for possibly creating new approach to produce metallic thin film with nano-sized grains by the NCP concept.

\section{Acknowledgements}

The authors would like to acknowledge the financial supports from the National Basic Research Program of China (2012CB937500) and from the National Natural Science Foundation of China (11572325).

\section{References}

[1] Bathias C, Paris PC. Gigacycle fatigue in mechanical practice. New York: Marcel Dekker; 2005.

[2] Sakai T. Review and prospects for current studies on very high cycle fatigue of metallic materials for machine structural use. J Solid Mech Mater Eng 2009;3:425-39.

[3] Schuller R, Fitzka M, Irrasch D, Tran D, Pennings B, Mayer H. VHCF properties of nitrided $18 \mathrm{Ni}$ maraging steel thin sheets with different $\mathrm{Co}$ and $\mathrm{Ti}$ content. Fatigue Fract Eng Mater Struct 2015;38:518-27.

[4] Shanyavskiy AA. Very-high-cycle-fatigue of in-service air-engine blades, compressor and turbine. Sci China - Phys Mech Astron 2014:57:19-29.

[5] Mughrabi H. Fatigue, an everlasting materials problem - still en vogue. Proc Eng 2010;2:3-26.

[6] Zimmermann M. Diversity of damage evolution during cyclic loading at very high numbers of cycles. Int Mater Rev 2012;57:73-91.

[7] Li SX. Effects of inclusions on very high cycle fatigue properties of high strength steels. Int Mater Rev 2012;57:92-114.
[8] Fitzka M, Mayer H, Schuller R, Stanzl-Tschegg SE, Przeorski T, Krug P. Variable amplitude loading of spray-formed hypereutectic aluminium silicon alloy DISPAL (R) S232 in the VHCF regime. Fatigue Fract Eng Mater Struct 2014;37:945-57.

[9] Chai GC, Zhou NA. Study of crack initiation or damage in very high cycle fatigue using ultrasonic fatigue test and microstructure analysis. Ultrasonics 2013;53:1406-11.

[10] Paolino DS, Tridello A, Chiandussi G, Rossetto M. On specimen design for size effect evaluation in ultrasonic gigacycle fatigue testing. Fatigue Fract Eng Mater Struct 2014;37:570-9.

[11] Murakami Yu, Nomoto T, Ueda T, Murakami Ya. On the mechanism of fatigue failure in the superlong life regime ( $N>10^{7}$ cycles), Part II: a fractographic investigation. Fatigue Fract Eng Mater Struct 2000;23:903-10.

[12] Sakai T, Sato Y, Oguma N. Characteristic S-N properties of high-carbonchromium-bearing steel under axial loading in long-life fatigue. Fatigue Fract Eng Mater Struct 2002;25:765-73.

[13] Lei Z, Xie J, Sun C, Hong Y. Effect of loading condition on very-high-cycle fatigue behavior and dominant variable analysis. Sci China - Phys Mech Astron 2014:57:74-82.

[14] Shyam A, Blau P, Jordan T, Yang N. Effect of submillimeter size holes on the fatigue limit of a high strength tool steel. Fatigue Fract Eng Mater Struct 2014;37:368-79.

[15] Sun C, Liu X, Hong Y. A two-parameter model to predict fatigue life of highstrength steels in a very high cycle fatigue regime. Acta Mech Sinica 2015;31:383-91.

[16] Shiozawa K, Lu L, Ishihara S. S-N curve characteristics and subsurface crack initiation behaviour in ultra-long life fatigue of a high carbon-chromium bearing steel. Fatigue Fract Eng Mater Struct 2001;24:781-90.

[17] Hong Y, Lei Z, Sun C, Zhao A. Propensities of crack interior initiation and early growth for very-high-cycle fatigue of high strength steels. Int J Fatigue 2014;58:144-51.

[18] Tanaka K, Akiniwa Y. Fatigue crack propagation behaviour derived from S-N data in very high cycle regime. Fatigue Fract Eng Mater Struct 2002;25:775-84.

[19] Murakami Yu, Nomoto T, Ueda T, Murakami Ya. On the mechanism of fatigue failure in the superlong life regime $\left(N>10^{7}\right.$ cycles), Part I: influence of hydrogen trapped by inclusions. Fatigue Fract Eng Mater Struct 2000;23:893-902.

[20] Shiozawa K, Morii Y, Nishino S, Lu L. Subsurface crack initiation and propagation mechanism in high strength steel in a very high cycle fatigue regime. Int J Fatigue 2006;28:1521-32.

[21] Sakai T, Oguma N, Morikawa A. Microscopic and nanoscopic observations of metallurgical structures around inclusions at interior crack initiation site for a bearing steel in very high-cycle fatigue. Fatigue Fract Eng Mater Struct 2015;38:1305-14.

[22] Grad P, Reuscher B, Brodyanski A, Kopnarski M, Kerscher E. Mechanism of fatigue crack initiation and propagation in the very high cycle fatigue regime of high-strength steels. Scripta Mater 2012;67:838-41.

[23] Chai G, Forsman T, Gustavsson F, Wang C. Formation of fine grained area in martensitic steel during very high cycle fatigue. Fatigue Fract Eng Mater Struct 2015;38:1315-23.

[24] Qian G, Zhou C, Hong Y. Experimental and theoretical investigation of environmental media on very-high-cycle fatigue behavior for a structural steel. Acta Mater 2011;59:1321-7.

[25] Sander M, Müller T, Lebahn J. Influence of mean stress and variable amplitude loading on the fatigue behaviour of a high-strength steel in VHCF regime. Int J Fatigue 2014;62:10-20.

[26] Sakai T, Sato Y, Nagano Y, Takeda M, Oguma N. Effect of stress ratio on long life fatigue behavior of high carbon chromium bearing steel under axial loading. Int J Fatigue 2006;28:1547-54.

[27] Kovacs S, Beck T, Singheiser L. Influence of mean stresses on fatigue life and damage of a turbine blade steel in the VHCF-regime. Int $\mathrm{J}$ Fatigue 2013;49:90-9.

[28] Lei Z, Hong Y, Xie J, Sun C, Zhao A. Effects of inclusion size and location on veryhigh-cycle fatigue behavior for high strength steels. Mater Sci Eng A 2012;558:234-41.

[29] Williams DB, Carter CB. Transmission electron microscopy: a textbook for materials science. 2nd ed. New York: Springer; 2009.

[30] Elber W. Fatigue crack closure under cyclic tension. Eng Fract Mech 1970;2:37-45.

[31] Antunes FV, Marques GAS, Chegini AG, Correia L. Transient behaviour in the numerical analysis of plasticity induced crack closure. Fatigue Fract Eng Mater Struct 2014;37:526-38.

[32] Ainsworth RA, Sharples JK, Smith SD. Effects of residual stresses on fracture behaviour-experimental results and assessment methods. J Strain Anal Eng Design 2000;35:307-16.

[33] Farahani M, Sattari-Far I, Akbari D, Alderliesten R. Effect of residual stresses on crack behaviour in single edge bending specimens. Fatigue Fract Eng Mater Struct 2013;36:115-26.

[34] Murakami Y, Kodama S, Konuma S. Quantitative evaluation of effects of nonmetallic inclusions on fatigue strength of high strength steels. I: Basic fatigue mechanism and evaluation of correlation between the fatigue fracture stress and the size and location of non-metallic inclusions. Int $\mathrm{J}$ Fatigue $1989 ; 11: 291-8$.

[35] Zhao A, Xie J, Sun C, Lei Z, Hong Y. Prediction of threshold value for FGA formation. Mater Sci Eng, A 2011;528:6872-7. 
[36] Zhao A, Xie J, Sun C, Lei Z, Hong Y. Effects of strength level and loading frequency on very-high-cycle fatigue behavior for a bearing steel. Int J Fatigue 2012;38:46-56.

[37] Valiev R. Nanostructuring of metals by severe plastic deformation for advanced properties. Nat Mater 2004;3:511-6.

[38] Estrin Y, Vinogradov A. Extreme grain refinement by severe plastic deformation: a wealth of challenging science. Acta Mater 2013;61:782-817.
[39] Berto F, Campagnolo A, Lazzarin P. Fatigue strength of severely notched specimens made of Ti-6Al-4V under multiaxial loading. Fatigue Fract Eng Mater Struct 2015;38:503-17.

[40] He Z, Kotousov A, Berto F. Effect of vertex singularities on stress intensities near plate free surfaces. Fatigue Fract Eng Mater Struct 2015;38:860-9. 